\title{
Origin and significance of the age dependence of calcite recrystallization rates in deep sea sediments
}

\author{
SHUO ZHANG ${ }^{1}$, DONALD DEPAOLO ${ }^{2}$ AND RENJIE \\ $\mathrm{ZHOU}^{3}$ \\ ${ }^{1}$ Tsinghua University \\ ${ }^{2}$ University of California, Berkeley, Dept of Earth and Planetary \\ Science \\ ${ }^{3}$ Texas A\&M University \\ Presenting Author: zhangs2019@tsinghua.edu.cn
}

Understanding the rate of carbonate diagenesis in calcite-rich deep sea sediments is key in interpreting isotopic and elemental ratios recorded in calcite sediment and understanding their implications for paleoclimate and global elemental cycles. We have used available pore fluid $\mathrm{Sr}$ and $\mathrm{Ca}$ concentration data from ODP archives for 20 drill sites in nearly pure carbonate sections to systematically estimate the calcite dissolution/precipitation rates. The concentration-depth curves are fit with a simple reactive transport model to retrieve reaction rate versus depth assuming an exponential depth dependence. The $\mathrm{Sr}$ data provide the exchange rate, or the rate of dissolution $\left(\mathrm{R}_{\mathrm{d}}\right)$ and precipitation $\left(\mathrm{R}_{\mathrm{p}}\right)$, where rates are expressed in units of fraction reacted per unit time $\left(\mathrm{Myr}^{-1}\right)$. The pore fluid $\mathrm{Ca}$ concentration data provide the difference $\left(R_{d}-R_{p}\right)$, which we refer to as the net reaction rate $\left(\mathrm{R}_{\text {net }}\right)$. When the model $\mathrm{R}_{\mathrm{d}}\left(\approx \mathrm{R}_{\mathrm{p}}\right)$ values are plotted against the average age of sediments to which they apply, an approximate 1/age relationship is obtained, with $\mathrm{R}_{\mathrm{d}} \approx \mathrm{b}$ /age and $\mathrm{b}=0.03$ to 0.1 . The larger data set conforms with a previously noted 0.1 age relationship found for a smaller number of sites [1] and silicate weathering in soils [2]. We show using both closed system and reactive transport models that the approach of pore fluid to equilibrium could come close to explaining the observed rate patterns in deep sea carbonates if calcite- pore fluid reaction rate is a function of $\left(1-\mathrm{Q} / \mathrm{K}_{\mathrm{eq}}\right)^{1+\mathrm{n}}$, and $\mathrm{n}$ is between 1 and 1.5. This higher order rate dependence is consistent with most laboratory calcite dissolution experiments [3], but our results require that it apply to exceedingly small departures from equilibrium (1 $\left.\mathrm{Q} / \mathrm{K}_{\mathrm{eq}}\right)<0.0001$, a regime that is not accessible through laboratory experimentation.

[1] Fantle \& DePaolo (2007), Geochimica et Cosmochimica Acta, 71(10): 2524-2546.

[2] Maher, DePaolo \& Lin (2004), Geochimica et Cosmochimica Acta, 68(22): 4629-4648.

[3] Adkins, Naviaux, Subhas, Dong \& Berelso (2021), Ann Rev Mar Sci, 13: 57-80. 